\title{
Differences in horizontal and vertical mismatches across countries and fields of study ${ }^{\mathrm{a}}$
}

\author{
Dieter Verhaest $^{\mathrm{b}}$, Sana Sellamic ${ }^{\mathrm{c}}$, Rolf Van der Velden ${ }^{\mathrm{d}}$
}

Postprint version, published in the International Labour Review.

DOI: $10.1111 / \mathrm{j} .1564-913 X .2015 .00031 . \mathrm{X}$

To be cited as: Verhaest, D., Sellami, S., \& Van der Velden, R. (2017), 'Differences in horizontal and vertical mismatches across countries and fields of study', International Labour Review, 156(1), 1-23.

\footnotetext{
${ }^{a}$ We are grateful to Piet Coppieters, Heidi Knippradt, Karel Neels, Walter Nonneman, Walter Van Trier, Mark Visser and participants of the Workshop of the European Network on Transitions in Youth in Nijmegen (2012) and the "Dag van de Sociologie" in Nijmegen (2013) for useful comments and suggestions on previous versions of this paper. This research is funded by the Flemish Government within the framework of the Policy Research Centre for Study and School Careers.

${ }^{\mathrm{b}}$ KU Leuven, Human Relations Research Group (HRRG), Belgium; Ghent University, Study Hive for Economic Research and Public Policy Analysis (SHERPPA), Belgium.

Corresponding author: Dieter Verhaest, KU Leuven, Faculty of Economics and Business, Warmoesberg 26, B1000 Brussels, Belgium; Email: dieter.verhaest@kuleuven.be

${ }^{c}$ KU Leuven, Human Relations Research Group (HRRG), Belgium; Antwerp University, Department of General Economics, Belgium.

${ }^{d}$ Maastricht University, Research Centre for Education and the Labour Market (ROA), The Netherlands.
} 


\begin{abstract}
We investigate to what extent differences in educational mismatches across countries and fields of study are explained by differences in labour institutions, educational institutions, and labour market imbalances. We rely on early career data for graduates in Europe and Japan and distinguish between full mismatch (FMM: field-ofstudy mismatch and overeducation combined), mere horizontal mismatch (HMM) and mere vertical mismatch (VMM). Mere HMM is found to be lower in countries with higher employment protection, higher unemployment benefits and more selective educational programs. For mere VMM, particularly differences in imbalances explain cross-country differences. Most country-level variables affecting mere HMM or VMM also affect FMM. In addition, FMM is positively related to collective bargaining coverage. Conclusions regarding field-of-study differences in mismatches are analogous, with both educational program characteristics and imbalances being explanatory factors.
\end{abstract}

\title{
Keywords
}

Field-of-study mismatch, overqualification, underemployment, youth labour markets 


\section{Introduction}

The (mis)match between education and work has been the focus of considerable research in the literature. Prior work concentrates primarily on vertical mismatch or overeducation (Groot and Maassen van den Brink, 2000; McGuinness, 2006). Recently, however, more interest has been shown in so-called "horizontal mismatch" as well - that is, mismatch between a worker's field of study and the content of his/her job (Wolbers, 2003; Robst, 2007). The bulk of the existing literature focuses on effects of mismatch, typically finding that mismatches are harmful in terms of wages and worker well-being (Hartog, 2000; Allen and van der Velden, 2001). There is also substantial evidence that the incidence of mismatch varies widely not only across individuals, but also across labor market segments by fields of study and across countries. At the micro level, research indicates that a variety of mechanisms are responsible for these inequalities, including a lower quality of human capital, job search constraints and discrimination (McGuinness, 2006). At more aggregate levels, a frequently suggested cause is imbalances between the demand and supply. At the macro level, the massive expansion of higher education in many Western countries is often held responsible; at the meso level, the higher incidence of mismatches among those with a humanities degree than among those with technical degrees suggests that students fail to choose fields of study that are in demand due to technological developments. However, whether these imbalances are truly responsible for the variation in mismatches at more aggregate levels largely remains to be investigated.

A small but growing body of research has begun to address this question through cross-country comparisons of the incidence of overeducation. In early work, Groot and Maassen van den Brink (2000) rely on meta-analysis to explain overeducation at the macro level. They find that the incidence of overeducation is positively related to the growth of the labor force. Another early contribution was presented by Di Pietro (2002), who use data from a panel of European countries to show that differences in overeducation across countries are related to the educational composition of the labor force, the strictness of employment protection legislation (EPL) and the level of R\&D investment. More recently, Verhaest and Van der Velden (2013) investigate country and field-ofstudy differences in overeducation among European graduates. Their results show that demand and supply conditions within the labor market as well as the institutional setting matter. First, they find evidence regarding the impact of structural imbalances between the demand and supply of educated workers on the incidence of graduate overeducation in a country. The supply of educated workers is not found to be important in itself, indicating that supply may create its own demand. Further, business cycle conditions at the time of labour market entry explain graduate overeducation as well. With respect to the educational institutions, they showed that both the orientation (general versus specialized) of the study program and the quality and selectivity of the study program are important in explaining country and field-of-study differences in overeducation. Finally, with respect to labor market institutions, Verhaest and Van der Velden do not find evidence that EPL influences overeducation. Similar conclusions regarding the role of structural imbalances, the business cycle and EPL are made by Croce and Ghighnoni (2012), who rely on data for the full labor force. Finally, the analysis of Davia, McGuinness and O'Connell (2010) confirms the aforementioned conclusions regarding structural imbalances of 
the quantity of skilled workers and the selectivity of the educational system. In addition, they find overeducation to be more prevalent among countries with a low union-density rate.

In this paper, we build on the existing literature by investigating what explains the differences in mismatches across countries and fields of study five years after graduation. Our analysis contributes to the literature in four new ways. First, we extend the analysis with horizontal mismatches. Apart from Wolbers (2003), who finds a positive correlation between the incidence of horizontal mismatches and unemployment, few studies have investigated cross-country differences in this type of mismatch. Moreover, no country-level studies have investigated horizontal and vertical mismatches simultaneously. Some research shows that in particular a combination of overeducation and field-of-study mismatch is harmful to wages and job satisfaction (see Robst, 2008; Béduwé and Giret, 2011). However, no evidence exists demonstrating a wage penalty for a mere field-ofstudy mismatch without overeducation. Hence, it seems that this last type of mismatch is less problematic for individuals, perhaps because it also indicates that workers are employable in a large range of occupations. Therefore, it is important to determine whether different combinations of horizontal and vertical mismatches are driven by different underlying mechanisms. Second, the present study accounts for differences in union bargaining coverage, rather than union density. The aforementioned finding that unionized countries have lower overeducation incidence seemingly contradicts the assumption that more rigid wage formation impedes labor market clearing. However, union density is only loosely correlated with the impact that unions have on the bargaining process. Union bargaining coverage is therefore likely to be a better indicator of wage rigidity. Third, our study considers the role of unemployment benefit policies. We hypothesize that countries with more generous unemployment benefits face lower levels of mismatches. Fourth, we much more deeply investigate what explains differences in mismatches between fields of study. The lower incidence of mismatch generally observed among individuals with a technical degree (in comparison to those with a humanities degree) may indeed be explained by technological change. An alternative explanation, however, may be that study programs differ across fields of study in terms of quality or selectivity and the extent to which they are vocationally or rather generally oriented. We disentangle the effect of differences in study program characteristics from the effect of structural imbalances between the demand and supply of field-of-study-specific labor.

For these analyses, we use REFLEX and HEGESCO data on graduates in 17 European countries and Japan. We apply multilevel analysis and consider a three-level nested structure: the individual level, the field-of-study level and the country level. We estimate a multinomial logit model with four outcome categories: "full match" (reference), "mere vertical mismatch" (only vertical but not horizontal), "mere horizontal mismatch" (only horizontal but not vertical) and "full mismatch" (both vertical and horizontal). The remainder of the paper is structured as follows. First, we develop our theoretical framework and hypotheses. Next, we explain the methodology, then give an overview of our results. Finally, we discuss the findings and offer conclusions. 


\section{Theoretical framework and hypotheses}

\section{Demand and supply context}

A first potential source of cross-country differences in mismatches is variation in the extent to which there is an overall imbalance between the demand and supply of skilled workers, either structurally or cyclically. There are two theoretical effects, which sometimes oppose each other (Bowlus, 1995). On the one hand, an oversupply of skilled workers may force job seekers to accept jobs below their level of education and outside their field of study. On the other hand, it allows employers to be more discriminating. Employers may prefer more highly educated and thus overeducated individuals (cf. Thurow, 1975; Okun, 1981), as well as individuals with the correct field of study (cf. Bowlus, 1995). This means that graduates with an "incorrect" field of study are forced to remain unemployed. Hence, an oversupply of skilled workers will lead to more overeducation, while the impact on horizontal mismatches is theoretically ambiguous. Several studies have shown that a structural oversupply of skilled workers indeed results in more overeducation (see Davia et al., 2010; Ghignoni, 2011; Croce and Ghignoni, 2012; Verhaest and Van der Velden, 2013). In addition, Croce and Ghighnoni find that at the country level, the business cycle affects the overall incidence of overeducation. Similarly, Verhaest and Van der Velden (2013) find that the business cycle in the year of labor market entry explains cross-country differences in overeducation up to five years after graduation; graduates find it difficult to find a verticallymatched job during an economic downturn. Only Wolbers (2003) investigates cross-country differences in horizontal mismatches; he finds that a high unemployment rate in the year of labor market entry increases the likelihood of horizontal mismatch. Following our theoretical considerations, we expect that the latter particularly results from the increased likelihood of a full mismatch. We thus test the following hypotheses.

H1: Countries with a structural oversupply (undersupply) of skilled workers face a higher (lower) incidence of mere vertical and full mismatch.

H2: Countries in a recession (economic boom) at the time graduates entered the labor market have a higher (lower) incidence of mere vertical and full mismatch.

Imbalances in supply and demand in terms of fields of study are also likely to explain mismatches. Individuals who face fierce competition for jobs within their field-of-study segment may be forced to accept jobs in other field-of-study segments with labor shortages or in labor market segments at lower job levels. Evidence for this hypothesis is provided by Wieling and Borghans (2001), who shows that a supply surplus for an educational type results in a higher percentage of overeducated graduates. More indirect evidence that educational mismatches result from imbalances in terms of fields of study is the finding that a graduate's field of study is a strong predictor whether he or she is likely to be overeducated or horizontally mismatched (see Dolton and Silles, 2003; Wolbers, 2003; Frenette, 2004; Ghignoni and Verashchagina, 2013). It is often reported that these mismatches are relatively infrequent among individuals in technical fields of study, and relatively frequent among those with a humanities or arts degree. A first cursory reason for this finding is that the differences in mismatches indeed result from pure quantitative imbalances. Most countries have a relatively low share of graduates choosing technical fields of study in comparison to humanities and arts (Oosterbeek and Webbink, 1997). Moreover, skill-biased technological change and the increasing importance of innovation may have 
further increased the demand for engineers and computer scientists. A second interpretation, however, is that differences in mismatches across fields of study are related to more qualitative differences between fields of study. Technical fields of study typically have more specialized programs (Wolbers, 2003) and are more selective (Rochat and Demeulemeester, 2001) than programs in the arts or humanities. Therefore, we test whether the differences in mismatches prevail even after accounting for differences in study program characteristics such as their orientation (general versus specialized) and their quality and selectivity.

H3: Graduates with a technical degree are, irrespective of the orientation and the quality and selectivity of their program, less likely to have any type of mismatch.

H4: Graduates with a Humanities and Arts degree are, irrespective of the orientation and the quality and selectivity of their program, more likely to have any type of mismatch.

\section{Educational institutions}

With respect to the role of these study program characteristics, we differentiate between within- and betweencountry effects. At the country level, we expect a negative relationship between the quality and selectivity of the educational system and the hiring standards adopted by employers (cf. Green et al., 2002). Accordingly, a high level of study program selectivity and quality at the country level will be associated with a lower amount of formal overeducation. Further, we expect that a high level of selectivity and quality is also associated with a lower prevalence of horizontal mismatches. In a country with a low selectivity and quality of educational programs, employers must rely more on additional training. Consequently, hiring employees whose field of study matches the work becomes less important. Within countries and fields of study, we expect that graduates of study programs that are less challenging and selective will be more inclined to accept any type of mismatch, since those graduates likely receive fewer suitable job offers. Employers confronted with graduates from a lowquality study program will be inclined to hire an overeducated one, but not necessarily one with a mere horizontal mismatch. Thus the within-country effect that study program selectivity and quality has on vertical mismatches is straightforward: the higher the selectivity and quality of the program, the lower the chance of vertical or full mismatch. However, for mere horizontal mismatches, the within-country effect of the quality and selectivity of the study program has a theoretically ambiguous sign. The negative relationship between the quality and selectivity of a study program and the incidence of vertical mismatch is well established empirically, both within countries (Robst, 1995; McGuinness, 2003; Di Pietro and Cutillo, 2006) and between countries (Davia et al., 2010; Verhaest and Van der Velden, 2013). Research regarding the impact of the quality and selectivity of the study program on horizontal mismatches, however, is lacking. We thus test the following hypotheses.

H5: Countries with a more selective and higher quality educational system have a lower incidence of any type of mismatch.

H6: Within countries, graduates from a more selective and higher quality study program are less likely to have a mere vertical or full mismatch. 
Regarding the orientation of the study programs (general versus specialized), we primarily expect an impact on horizontal mismatches. General study programs offer a wider array of skills that can be used across occupations. When employed in jobs for which they have a horizontal mismatch, graduates from this type of program will be relatively more productive than graduates from a specialized study program. Conversely, those with a more specialized study program will be relatively more productive in the case of a horizontal match (Wolbers, 2003). Further, general programs usually focus more on learning and analytical skills and less on directly applicable skills. Hence, even if graduates of general study programs manage to find a job that matches their field of study, they are more often required to start in a lower level job to gain some practical work experience before being promoted to a higher position (cf. Sicherman and Galor, 1990). Moreover, given that general degrees provide less clear signals of the occupation-specific skills of graduates, employers may use lower-level jobs as a screening device for the higher-level jobs (cf. Ghignoni and Verashchagina, 2013). The effect that the orientation of the study program has on mere vertical mismatch is thus likely to be stronger for graduates who recently entered the labor force than for graduates who finished their program five years ago. Nevertheless, Verhaest and Van der Velden (2013) find that the effect of the study program's orientation on overeducation remains significantly positive five years after graduation. This is likely explained by the fact that graduates of these programs face a higher likelihood of a full mismatch.

H7: Countries with a more generally oriented educational system have a higher incidence of mere horizontal and full mismatch among graduates five years after finishing their program.

H8: Within countries, individuals with a more generally oriented study program are more likely to have a mere horizontal or full mismatch five years after finishing their program.

\section{Labor market institutions}

Labor market institutions also deliver a potential explanation for differences in mismatches across countries. First, we investigate the role of EPL. EPL reduces the employers' ability to replace badly matched employees with well-matched job seekers. Employers are likely to anticipate these problems. A job candidate's level of education and field of study provide signals to employers regarding the candidate's level and type of abilities and talents. Therefore, employment of an individual with the "wrong" field of study carries a huge risk for a firm in terms of productivity losses. Consequently, we expect that employers will not be inclined to hire these kinds of job seekers if firing costs are high. Furthermore, one may expect that employers in countries with strong EPL rely more on internal promotion to place employees in the right kind of job. In these countries, we thus expect higher levels of overeducation for newcomers within the labor market. As stated in the introduction, evidence by Di Pietro (2002), Croce and Ghighnoni (2012) and Verhaest and van der Velden (2013) regarding the impact that EPL has on overeducation is inconclusive. One potential issue is that none of these studies differentiate between merely vertically mismatched individuals and those who are fully mismatched. We thus form the following hypothesis.

H9: Countries with a higher level of employment protection face a lower incidence of mere horizontal mismatch and a higher incidence of mere vertical mismatch. 
Second, also differences in unemployment benefit regimes may explain country-level differences in mismatches. More generous unemployment benefits allow job seekers to be more selective, resulting in fewer mismatches. While the analysis of Croce and Ghighnoni (2012) does not confirm this, their analysis is based on data for the full labor force. Given that unemployment is generally higher for young individuals, the unemployment benefit regime may be more important for the sample that is investigated in our study.

H10: Countries with more generous unemployment benefits have a lower incidence of any type of mismatch.

Finally, we investigate the role of collective bargaining coverage ${ }^{\mathrm{e}}$ as indicator for wage rigidity. As McGuinness (2006) argues, wage rigidity impedes market clearing, resulting in more mismatches. Croce and Ghighnoni (2012) also point to another effect resulting from the impact that relative wages have on the opportunity cost of mismatches (cf. Gottschalk and Hansen, 2003). This effect may work in two directions. On the one hand, unions may bargain above-competitive wages for high-skilled jobs, resulting in increased opportunity costs of overeducation. On the other hand, unions may have a preference for wage compression and bargain for abovecompetitive wages for low-skilled jobs, resulting in decreased opportunity costs. Croce and Ghighnoni provide evidence that the latter mechanism dominates. They show that the relative wages of tertiary education graduates have a negative impact on the incidence of overeducation, while relative wages are in turn found to be negatively affected by union bargaining coverage. This conclusion seems to conflict with the results of Davia et al. (2010), who find that higher union density may result in lower levels of overeducation. However, as previously stated, union density is an imperfect measure of unions' influence on the bargaining process. Hence, we hypothesize that collective bargaining coverage has a positive effect on mere vertical and full mismatch. ${ }^{\mathrm{f}}$ Regarding the impact of collective bargaining coverage on mere horizontal mismatch, similar mechanisms can be considered. On the one hand, flexible wages may help labor market clearing, thus reducing the incidence of mismatch. On the other hand, flexible wages may facilitate the assignment of individuals to the occupations most in demand on the labor market, even if those job seekers do not have a matching field of study. The overall effect is thus theoretically ambiguous. Given that previous empirical evidence is lacking, we therefore do not formulate a hypothesis regarding this type of mismatch:

H11: Countries with higher collective bargaining coverage have higher incidence of mere vertical mismatch and full mismatch.

\footnotetext{
e Collective bargaining coverage is an indicator of the extent to which the terms of workers' employment are influenced by collective negotiation.

${ }^{\mathrm{f}}$ An alternative approach may be to include relative wages and to use collective bargaining coverage as an instrumental variable to account for endogeneity, following Croce and Ghighnoni (2012). However, comparative data on wages for lower segments by field of study are lacking. Moreover, applying an instrumental variable approach within a multilevel multinomial logit model would significantly complicate estimation. Therefore, we elect to estimate a reduced-form specification in which collective bargaining coverage is directly included.
} 


\section{Methodology}

\section{Data and mismatch measurement}

The analysis is based on data from the REFLEX and HEGESCO surveys. The REFLEX survey was conducted among graduates in 15 countries: Austria, Belgium - Flanders, the Czech Republic, Estonia, Finland, France, Germany, Italy, Japan, the Netherlands, Norway, Portugal, Spain, Switzerland and the UK. ${ }^{\mathrm{g}}$ The survey was conducted in 2005 using a representative sample of graduates of higher education programs who received their degrees in the 1999-2000 academic year. HEGESCO is a related survey that was carried out in 2008 among individuals who graduated during the 2002-2003 academic year in five Central- and Eastern-European countries: Hungary, Lithuania, Poland, Slovakia and Turkey. The data include detailed information about each respondent's study program, first employment after graduation and employment at the time of the survey (see Allen and Van der Velden, 2011). We exclude Lithuania and Turkey from our analysis, because not all aggre gate indicators used in this study are available for those two countries. Further, we focus on individuals who are employed five years after graduation and exclude those who attend any other tertiary program after graduation. Finally, in order to avoid overrepresentation of certain countries, we confine the sample of the multivariate analysis to a maximum of 2,000 randomly chosen cases per country. Omitting observations with missing values leaves a final sample of 14,398 individuals.

To determine the match status, we rely on self-assessments. To identify vertical mismatches, respondents were asked: "What type of education do you feel was most appropriate for this work?" The graduates could choose between a number of (sub)levels of education. When the appropriate level as assessed by the respondent is lower than the education level of the graduate, he/she is considered to be overeducated. To simplify the analysis, the undereducated are grouped with individuals whose level of education matched the type they listed as being

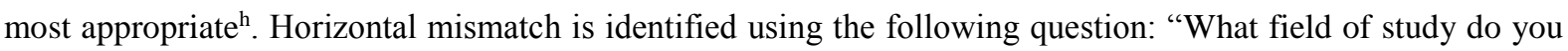
feel was most appropriate for this work?" Here, respondents could choose between: (1) exclusively own field, (2) own or a related field, (3) a completely different field or (4) no particular field. The first two answers are defined as a horizontal match and the other two as a horizontal mismatch. By combining the two types of mismatches, we obtain the four (mis)match categories defined previously.

Table 1 reports the incidence of the different types of mismatch by country for respondents' jobs five years after graduation. On average, countries had a nearly identical incidence of full mismatch and mere vertical mismatch-each at $8 \%$. The average incidence of mere horizontal mismatch is somewhat higher-just over $10 \%$. However, these numbers differ substantially across countries. On the one hand, countries like Portugal, Norway, Finland, France, Switzerland and Slovenia each have an overall mismatch incidence of less than $20 \%$. On the other hand, countries like the UK, Hungary, Spain, Poland and particularly Japan show a substantially higher incidence of mismatch. There are also substantial differences across countries in the distribution of the incidence of the three types of mismatch. Some countries had a relatively high incidence of one type of

\footnotetext{
${ }^{g}$ Sweden took also part in the REFLEX project, but using a different experimental design; Swedish data are hence not comparable.

${ }^{\mathrm{h}}$ This decision is justified by the finding that the earnings and job satisfaction of undereducated individuals is typically at least as high as that of adequately educated individuals (see Hartog, 2000; Verhaest and Omey, 2009).
} 
mismatch, but a relatively low incidence of another type of mismatch. Japan, for instance, exhibits very high incidence of mere horizontal and full mismatch, but rather low incidence of mere vertical mismatch. Similarly, Estonia faces a relatively high incidence of mere horizontal mismatch and a relatively low incidence of mere vertical mismatch. Unlike Japan however, Estonia's incidence of full mismatch is relatively low.

[Insert Table 1 here]

\section{Estimation and model specification}

We estimate the determinants of mismatch using a multilevel multinomial logit model. We consider a three-level nested structure: individuals (i) are nested in fields of study (f), which are in turn nested in countries (c). Several models with the following general form are considered:

$Y_{i f c}^{k}=\mathbf{X}_{\text {ifc }} \beta_{1}^{\mathbf{k}}+\mathbf{F}_{\mathrm{fc}} \boldsymbol{\beta}_{2}^{\mathbf{k}}+\mathbf{C}_{\mathrm{c}} \boldsymbol{\beta}_{3}^{\mathbf{k}}+R_{i f c}^{k}+U_{f c}^{k}+V_{c}^{k}$

where $Y^{k}$ is a latent variable for mismatch category $k$ (full match is the reference category), $\mathbf{X}$ is a vector of individual characteristics, $\mathbf{F}$ is a vector of field-of-study-level characteristics, $\mathbf{C}$ is a vector of country-level characteristics and $R^{k}, U^{k}$ and $V^{k}$ are level-specific error terms. The number of groups is 18 countries and 142 fields-of-study segments. ${ }^{i}$ While $R^{k}, U^{k}$ and $V^{k}$ are assumed to be random and thus independent from one another, we account for possible interdependence of errors within levels and across mismatch categories. ${ }^{j}$ We also estimate a standard binary logit model that groups the three mismatch categories into one category (i.e., match versus mismatch).

In order to assess how different types of variables explain the variances, we build our model iteratively. Model 0 , our baseline model, only contains an intercept and the country-level random effect $\left(V^{k}\right)$. In Model 1 , we include covariates that are measured at the individual level $(\mathbf{X})$. The covariates include a dummy for gender, the age of the graduate, a dummy for whether the degree of the graduate provides access to a PhD program ${ }^{\mathrm{k}}$ and the relative study results within one's country. ${ }^{1}$ Hypotheses 6 and 8 refer to within-country differences in the effect of study programs. These can be related to differences between fields of study as well to differences between study programs in the same field of study. To test the effect of study program characteristics within fields of

\footnotetext{
${ }^{\mathrm{i}}$ Within each country we delineate a maximum of eight fields of study: (1) education, (2) humanities and arts, (3) social sciences, business and law, (4) science, mathematics and computing, (5) engineering, manufacturing and construction, (6) agriculture and veterinary, (7) health and welfare and (8) services. No observations of subject (8) existed for Japan and Switzerland. Six individuals in the sample followed a general program; these individuals are excluded.

$\mathrm{j}$ The models are estimated using the runmlwin command implemented in Stata by Leckie and Charlton (2011) to fit multilevel models in the MLwiN software package (Rashbash et al., 2009).

${ }^{\mathrm{k}}$ This largely coincides with distinguishing between bachelor's and master's programs. Note, however, that the respondents of the REFLEX/HEGESCO survey left education in the pre-Bologna era, so the term bachelor or master is misleading.

${ }^{1}$ This last variable is based on the respondents' assessment of their grades in the year of graduation relative to other students. In the Japanese version, individuals were asked about their absolute grade, while in the other versions, respondents were asked about their relative grade. We create a compatible variable by creating a standardized measure for Japanese and non-Japanese self-assessed performance. Missing values are imputed by their expected values using OLS regression.
} 
study on mismatch, we include the deviation of the quality and selectivity of an individual's study program from the average quality and selectivity of the study program of his/her field of study. We also include a similar variable with respect to the orientation (general versus specialized) of the study program. These two variables are derived from a principal component analysis of the answers of respondents' assessments of six aspects of the content of their study program (see Appendix A for the factor loadings). The factor scores of the two extracted factors are used as proxies for the quality and the relative orientation of the study program.

In Model 2, we include the random effects at the level of field of study $(R)$. Model 3 adds covariates that are measured at the field-of-study level (F). These field-of-study-level covariates are seven field-of-study dummies (with Education as reference category) and the field-of-study deviations of the field-of-study average quality and orientation of the study program from their country-level averages. Together with the aforementioned indicators of the quality and selectivity of study programs within fields of study, we can test Hypothesis 6 and 8. Moreover, by including field-of-study dummies as well as the orientation and quality and selectivity of fields of study within a country, we assess whether differences in mismatches between humanities and technical degrees result from differences in study program characteristics (cf. Hypothesis 6 and 8) or from structural imbalances between the demand and supply of field-of study-specific labor (cf. Hypothesis 3 and 4).

In Model 4, we also account for country-level variables (C). First, to account for differences in educational institutions (Hypothesis 5 and 7), we include the average country scores for the quality and selectivity and the orientation of the program. Our measures for the structural supply and demand of skilled workers (cf. Hypothesis 1) are the share of highly educated individuals age 25 or older as measured by Barro and Lee (2001) and the gross domestic expenditure on R\&D as measured by the OECD (2008). ${ }^{\mathrm{m}}$ The (relative) structural oversupply of skilled workers is assessed by the difference between the standardized values of these two indicators. We also include the output gap - that is, the relative difference between the actual and the potential GDP - as an indicator of the business cycle (Hypothesis 2). This variable is developed by the OECD and measured in the year of labor market entry (2000 or 2003, depending on the survey). We test Hypothesis 9 by using a composite measure of the OECD (2004) on the overall strictness of EPL. To measure how generous unemployment benefits are in a country, we include the replacement ratio (cf. Hypothesis 10). The replacement ratio is the proportion of expected income from work that is replaced by unemployment and related welfare benefits and is reported by the OECD (2010). Finally, for the measurement of collective bargaining coverage (cf. Hypothesis 11), we rely on data from Venn (2009).

\section{Estimation results}

\section{Variance decomposition}

In Table 2 we report the variance decomposition of the estimated multinomial logit models. Our baseline model (Model 0) indicates that the country level is responsible for $14 \%$ of the overall variation in mere horizontal

\footnotetext{
${ }^{\mathrm{m}}$ Both are for the year 2000. Because of missing information, the R\&D expenditures of Norway are for the year 2001.
} 
mismatch and $10 \%$ of the overall variation in full mismatches across individuals. The country level is much less important in explaining the incidence of mere vertical mismatch. The residual country-level variance of mere vertical mismatch and full mismatch increases slightly after including the individual-level variables (Model 1). It thus seems that the importance of country-level effects in explaining the incidence mere vertical mismatch and full mismatch is somewhat underestimated due to compositional effects. The opposite seems to be true for mere horizontal mismatch. In Model 2, we also include the random effects at the field-of-study level. The field of study is found to be a significant driver of full mismatch (13\% of the overall variance), but somewhat less important in explaining mere vertical mismatch $(5 \%)$ and mere horizontal mismatch $(6 \%)$. After including fieldof-study-level variables as well (Model 3), the unexplained field-of-study-level variance is largely eliminated for full and mere horizontal mismatch. In the case of mere vertical mismatch, however, an unexplained field-ofstudy-level variance of $3.4 \%$ remains. Factors other than field of study and program characteristics are thus responsible for differences in mere vertical mismatch across fields of study. Also interesting is the change in the unexplained country-level variance after including field-of-study-level variables and random effects (Model 1 versus Model 3). This unexplained variance drops substantially both for mere horizontal mismatch (from $11 \%$ to $8 \%$ ) and for full mismatch (from $11 \%$ to $8 \%$ as well). This indicates that a substantial part of cross-country variation can be attributed to differences in the extent to which graduates within countries enroll in fields of study that are associated with low mismatch probabilities. Finally, in Model 4, we also include the variables that are measured at the country level. This largely eliminates the unexplained gross variation between countries for all types of mismatches.

[Insert Table 2 here]

\section{Main estimation results}

Table 3 presents the estimation results for the full multinomial logit model specification (Model 4). ${ }^{\mathrm{n}}$ The binary logit model results on the likelihood to have any type of mismatch are not reported in detail, but are available upon request. Before we turn to the variables of interest, we first briefly describe the other results. Regarding the variance-covariance matrix of our model, we find that most variances remain statistically significant. Including random effects is thus justified. Further, the covariance estimates indeed suggest some interdependence between mismatch categories.

With respect to the individual-level characteristics, we are primarily interested in the impact of the study program characteristics on mismatch. Our results support the hypothesis that individuals who graduate from a study program that is of above average quality are less likely to have a mere vertical or a full mismatch in their current job (cf. Hypothesis 6). Our estimates also show a negative impact of the quality of the study program on the likelihood that an graduate will have a horizontal mismatch. The results with respect to the relative orientation of the study program are only partially in line with Hypothesis 8. Individuals graduating with a relatively general study program are more likely to be merely horizontally mismatched. However, we do not find statistically significant evidence regarding the likelihood of full mismatch. Regarding the other included

\footnotetext{
${ }^{\mathrm{n}}$ To save space, we do not report the estimation results for the other specifications. These results are available upon request.
} 
individual characteristics, we find that females and older graduates have a higher likelihood of being merely vertically mismatched or fully mismatched. Further, individuals who receive a degree that does not provide access to a PhD program show a lower probability of being merely vertically mismatched, but a higher probability of being merely horizontally mismatched. Finally, we find that individuals with better study results have a higher likelihood of finding a good match five years after graduation. This result mirrors our findings on the quality and selectivity of the study program; any variable suggesting a low quality of human capital increases an individual's risk of all types of mismatch.

\section{[Insert Table 3 here]}

The results regarding the program characteristics measured at the field-of-study level further corroborate the important role played by signals of quality of human capital. Graduates from fields of study with relatively more selective and higher quality programs experience lower incidence of all types of mismatches. We further find that graduating from a relatively general study program increases the likelihood to having a mere horizontal mismatch. Study program orientation does not have a statistically significant effect on the incidence of full mismatch. However, our results also indicate that graduates in fields of study with a general study program face a lower incidence of mere vertical mismatches. Finally, our results show that individuals with humanities and arts degrees have the highest likelihood of a full mismatch, and rank second and third of all fields of study in terms of mere horizontal and mere vertical mismatch, respectively. ${ }^{\circ}$ This seems largely in line with Hypothesis 4. However, our hypothesis regarding graduates with a technical degree (Hypothesis 3) is not supported. We indeed find that, conditional on the orientation and quality of the study program, graduates with a degree in engineering, manufacturing or construction are relatively less likely to have a full mismatch (five out of seven fields of study perform significantly worse; the other two have a statistically indistinguishable likelihood of full mismatch). These graduates' likelihood of a mere horizontal mismatch is relatively low, although graduates with a health and welfare degree fare significantly better. However, graduates from engineering fields of study are significantly more likely (than five out of the other seven fields of study) to have a mere vertical mismatch. Moreover, for graduates of science, mathematics and computing, we find an increased incidence of full mismatches. The unreported binary logit results on the likelihood of any type of mismatch reject Hypothesis 3; while graduates with an engineering, manufacturing and construction degree perform significantly better on this outcome compared to those with a humanities and arts degree, they also perform significantly worse than those with an education degree or health and welfare degree. To assess the extent to which these outcomes can be attributed to the fact that we account for the average quality and orientation of programs in each field of study, we also estimate a reduced-form model that excludes these study program variables. ${ }^{p}$ Differences in mere vertical mismatch across fields of study are much less pronounced if we do not control for study program characteristics. Nevertheless, this specification still finds that engineering, manufacturing and construction graduates face higher mere vertical mismatch than education and health and welfare graduates.

\footnotetext{
${ }^{\circ}$ The difference is statistically significant $(\mathrm{p}<0.10)$ in comparison to all other fields of study for full mismatches and in comparison to six out of eight other fields of study for mere horizontal mismatches. However, regarding mere vertical mismatch, only the difference with education turns out to be statistically significant.

$\mathrm{p}$ To save space, the results are not reported, but they are available upon request.
} 
Also at the country level, we find that the selectivity and quality of human capital is an important predictor of mismatches. The likelihood of full mismatch or mere horizontal mismatch is lower for individuals in countries with more selective and higher quality educational systems (cf. Hypothesis 5). Regarding mere horizontal mismatch, this between-country effect is even more pronounced than the within-country effects. The opposite seems to be true regarding mere vertical mismatch, as we do not find any evidence that the quality and selectivity of the educational system at the country-level affects this type of mismatch. However, some caution is recommended regarding this conclusion; the difference between the country-level and field-of-study-level effect is only statistically significant at the $10 \%$ level. With respect to the orientation of the educational system in each country, we note some differences between the within-country effects and the between-country effect. Countries with more a generally oriented system show a higher incidence of full mismatch. Although this outcome supports Hypothesis 7, we do not find any statistically significant evidence for mere horizontal mismatch.

Besides these two characteristics of the educational system, we distinguish two other groups of country-level factors: the supply and demand context and labor market institutions. Our results indicate that countries that face a structural oversupply of skilled workers have a higher incidence of mere vertical and full mismatch (cf. Hypothesis 1). The reverse is true for countries that are in an economic upswing (positive output gap; cf. Hypothesis 2). We find that neither type of imbalance has a significant impact on mere horizontal mismatch. The outcomes with respect to employment protection and unemployment benefits are only partially in line with our predictions. As expected, we find a higher level of employment protection and higher replacement ratios are both associated with a lower incidence of mere horizontal mismatch (cf. Hypothesis 9 and 10), though their estimated effects on the other two types of mismatches are statistically insignificant. The unreported results on the binary logit analysis reveal that employment protection has a statistically significant $(\mathrm{p}<0.10)$ impact on the likelihood of full match. Finally, collective bargaining coverage has a significantly positive effect on the likelihood of full mismatch (cf. Hypothesis 11), but does not have a statistically significant effect on the likelihood of mere horizontal or mere vertical mismatch.

\section{Sensitivity analyses}

Given that a few pairs of country-level variables have substantial correlations ${ }^{\mathrm{q}}$, some of the results may be responsive to the inclusion of other variables. Therefore, as a sensitivity analysis, we also estimate a reduced model based on stepwise backward elimination of insignificant country-level variables. ${ }^{\mathrm{r}}$ Table 4 presents the results obtained from this analysis. All results regarding the supply and demand context, the characteristics of the educational system and the replacement ratio are consistent with the outcomes of our full model. However, with respect to EPL and collective bargaining coverage, there are some clear differences. While the full model found that employment protection has only a significant impact on mere horizontal mismatch, the reduced

\footnotetext{
${ }^{\mathrm{q}}$ These correlations are available upon request.

${ }^{\mathrm{r}}$ In another sensitivity analysis, we re-estimate our full model specification omitting data from Japan. Compared to other countries, Japan shows a substantially higher incidence of mere horizontal mismatches (see Table 1). The only change in results are some differences with regard to the impact of educational system characteristics. We did not find that the quality and selectivity of the educational system and its orientation has a statistically significant impact on the incidence of full mismatch. These estimation results are available upon request.
} 
model suggest that employment protection also has significant positive effects on the other two types of mismatches. The reduced model also shows that collective bargaining coverage has a statistically significant effect on mere vertical mismatch (cf. Hypothesis 11).

[Insert Table 4 here]

\section{Discussion and conclusion}

This study is designed to determine what explains country and field-of-study differences in educational mismatches five years after graduation. In contrast to other studies, we analyze horizontal and vertical mismatches simultaneously, defining three mismatch categories: mere vertical mismatch, mere horizontal mismatch, and full mismatch. We investigate three types of explanatory factors: those related to the demand and supply context, educational institutions and labor market institutions.

Regarding the demand and supply context, we find that both cyclical and structural country-level imbalances drive the incidence of mere vertical and full mismatch, but not mere horizontal mismatch. The effect of these imbalances on overeducation is in line with the outcomes of several other studies, and indicates that graduates are prepared to accept lower-level positions when they face difficulties finding jobs aligned with their level of education. Further, the absence of an effect of these imbalances on mere horizontal mismatch suggests that the positive effect resulting from an increased willingness to accept such positions is offset by an equally large negative effect resulting from an increase in employers' selectivity (cf. Bowlus, 1995).

Also differences in mismatch between fields of study seem to be explained by imbalances between demand and supply. In particular, graduates with an arts and humanities degree are more likely to have any type of mismatch. Given that these higher incidences remain even after accounting for differences in the selectivity and orientation of the study programs, it seems that the source of this negative labor market performance is at least partly quantitative - that is, labor supply outstrips the demand for graduates with arts and humanities qualifications. Graduates with a technical degree are less likely to have a mere horizontal or full mismatch. However, after accounting for the selectivity and the rather specialized orientation of the study programs within technical fields of study, we find that graduates of these programs are more likely to have a mere vertical mismatch than graduates from most other fields of study. This suggests that the shortage of job seekers with a technical education is mainly concentrated at more intermediate and undergraduate levels. Still, this requires further investigation.

Concerning educational characteristics, we first consider the quality and selectivity of study programs. Within countries, we find that a lower quality and selectivity of the study program increases graduates' likelihood of having any type of mismatch. Similarly, lower grades increase a graduate's likelihood of having any type of mismatch. The finding that individuals with a lower quality of human capital are more likely to be overeducated was expected, and fits with the conclusions of many other studies in the literature. However, the effect for mere horizontal mismatch was not anticipated and does not match with the idea that a mere horizontal mismatch is a less severe problem because it is a sign of higher employability. It may be likely that employers hire these 
graduates due to a shortage of candidates with a matching field of study. Also in terms of the differences in mismatches between countries, we find evidence that the quality and selectivity of the educational system matters. However, contrary to our expectations, we find no evidence of between-country effects on mere vertical mismatch. One explanation may be that our quality indicator insufficiently captures quality differences across countries if individuals base the assessment of the quality of their study program only on a within-country comparison. However, in that case, we would not expect to find that the country-level average quality has an effect on the other two types of mismatches either. An alternative explanation may be provided by the subjective nature of our overeducation measure. To the extent that the overall quality of the educational system is perceived to be poor, individuals may adapt upward their assessment of what is required to execute their jobs. Hence, improving the overall quality of the educational system may result in less formal overeducation, but not in less genuine overeducation (cf. Chevalier, 2003). Further evidence, relying on more objective indicators may resolve this.

The results with respect to the orientation of the educational system are less straightforward. Looking at differences within countries, we find that a general orientation increases the incidence of mere horizontal mismatch. Looking at differences between countries, a general orientation increases the incidence of full mismatch. These effects were expected, since general programs may provide more skills that can be used across occupations. However, our results did not reveal a similar within-country effect on full mismatch or a similar between-country effect on mere horizontal mismatch. With respect to mere vertical mismatches, we find an unanticipated negative within-country effect. This seems to suggest that although graduates with a general education more often face a horizontal mismatch, they are not more likely to be overeducated. This might be explained as follows: if it is the case that graduates cannot find a job that matches their education, those with a general education are more likely to switch to jobs outside their field of study than those with a vocational education. While the implication may be that these generally educated graduates must start their career in a position below their level of education, they are more often promoted to a higher position after several years. ${ }^{\mathrm{s}}$

Labor market institutions play an important role in determining cross-country differences in mismatches as well. First, we find that strict EPL decreases the incidence of mere horizontal mismatch five years after graduation. This fits with the expectation that employers are reluctant to hire graduates from non-matching fields of study since these individuals do not provide any reliable signal regarding their productivity. After all, dismissal will be difficult or costly when the result of the screening process turns out to be negative. We expected that in countries with strong employment legislation, employers would rely more on internal promotions, thus increasing the likelihood of mere vertical mismatches. This was not confirmed in our analyses. It may be the case that employers also perceive employment of merely vertically mismatched individuals to be risky. Individuals may become dissatisfied with their job if they are not promoted (cf. Béduwé and Giret, 2011), thus demotivating these employees and making them less productive. It is noteworthy that our outcomes regarding mere vertical mismatch differ from those of other studies, including Di Pietro (2002), Croce and Ghighnoni (2012) and Verhaest and Van der Velden (2013). A possible explanation is that these other studies focus on the full labor

${ }^{\mathrm{s}}$ Unreported estimates on match status in the first job after graduation are consistent with this interpretation. We find no significant withincountry effect of general study programs on mere vertical mismatch and a significantly positive within-country effect on mere horizontal and full mismatch. These estimates are available upon request. 
force. To the extent that individuals cannot be fired after organizational and technological changes, match quality may be poorer for older employees than for younger employees. Another explanation is that these studies may not account for other labor market institutions that are correlated with EPL, such as unemployment benefits and collective bargaining coverage.

Our findings are also novel with regards to the effects of the generosity of the unemployment benefit system and collective bargaining coverage. We find that a higher replacement ratio decreases the country-level incidence of mere horizontal mismatches five years after graduation. This suggests that higher unemployment benefits allow job seekers to be more selective. We also find that higher bargaining coverage results in a higher incidence of full mismatch. This conforms with the results of Croce and Ghighnoni (2012), and can result both from downward wage rigidity in skilled jobs and from wage compression. The finding that collective bargaining coverage has no impact on the incidence of horizontal mismatches suggests that the positive effect of wage rigidity, which prevents demand to adapt to supply, is compensated by the negative effect of wage compression, resulting in a lower willingness among job seekers to take jobs outside their field of study.

In sum, this study shows that differences in educational mismatches across countries and fields of study are driven by a broad range of mechanisms. This creates a clear challenge for policy makers and indicates that a combination of economic, education, and labor market policies may be needed to successfully reduce mismatches among young workers. This is particularly true for full mismatches, which can be considered the most problematic. A first policy measure may be to invest in the quality of the study programs. Also the provision of study-choice guidance and information regarding the fields of study most in demand on the labour market may be helpful to reduce mismatches. Further, governments may increase financial support for R\&D investments (see also Ghignoni and Verashchagina, 2013), which may increase the overall demand for graduates and reduce possible structural imbalances. While the above-mentioned measures may be rather uncontroversial, other measures may conflict with alternative priorities such as combating youth employment. Increasing unemployment benefits, for instance, may help young people finding jobs that match with their field of study. However, this may also reduce the incentive to search for jobs. Similarly, while we found high degrees of EPL to be associated with lower incidences of mismatch, stronger EPL may also increase the bargaining power of insiders on the labour market thus reducing the chances to find a job in the first place. Further research would be helpful in providing more insight into these issues. 
Appendix A: Derivation of the quality and selectivity and the general orientation of the study program: Principal Components rotated factor loadings

To what extent did the following descriptions apply to your study program

Component 1:

Component 2:

program

Program was generally regarded as demanding

Employers are familiar with the content of program

Quality and

General

selectivity

orientation

There was freedom in composing your own program

,365

, 430

, 113

$-, 179$

$-, 092$

Program had a broad focus

, 016

,587

Program was vocationally orientated

,407

,282

Program was academically prestigious

,299 


\section{References}

Allen, J., van der Velden, R. (2001), 'Educational mismatches versus skill mismatches: effects on wages, job satisfaction, and on-the-job search', Oxford Economic Papers, 53, 434-452.

Allen, J., van der Velden, R. (2011), The Flexible Professional in the Knowledge Society: New Challenges for Higher Education, Higher Education Dynamics, 35, Dordrecht: Springer.

Barro, R., Lee, J. (2001), 'International data on educational attainment: updates and implications', Oxford Economic Papers, 53, 541-563.

Béduwé, C., Giret, J. (2011), 'Mismatch of vocational graduates: what penalty on French labour market?' Journal of Vocational Behavior, 78, 68-79.

Bowlus, A.J. (1995), 'Matching workers and jobs: cyclical fluctuations in match quality', Journal of Labor Economics, 13, 335-350.

Chevalier, A. (2003), ‘Measuring over-education', Economica, 70, 509-531.

Croce, G., Ghignoni, E. (2012), 'Demand and supply of skilled labour and overeducation in Europe: a countrylevel analysis', Comparative Economic Studies, 54, 413-439.

Davia, M., McGuinness, S., O’Connell, P. (2010), 'Explaining international differences in rates of overeducation in Europe', ESRI Working Paper, No. 386, Dublin.

Di Pietro, G. (2002), 'Technological change, labor markets and low skill, low-technology traps', Technological Forecasting \& Social Change, 69, 885-895.

Di Pietro, G., Cutillo, A. (2006), 'University quality and labour market outcomes in Italy', Labour, 20, 37-62.

Dolton, P., Silles, M. (2003), 'The determinants and consequences of graduate overeducation', in Büchel, F., de Grip, A., Mertens, A. (Eds.) Overeducation in Europe, Edward Elgar, Cheltenham, pp. 189-213.

Frenette, M. (2004), 'The overqualified Canadian graduate: the role of the academic program in the incidence, persistence, and economic returns to overqualification', Economics of Education Review, 23, 29-45. 
Ghignoni, E. (2011), 'Demand and supply of skilled labour and persistence of young workers' overeducation in Europe: Mediterranean Countries versus the Netherlands', Journal of Educational, Cultural and Psychological Studies, 4, 101-143.

Ghignoni, E., Verashchagina, A. (2014), 'Educational qualifications mismatch in Europe. Is it demand or supply driven?' Journal of Comparative Economics, 42, 670-692.

Gottschalk, P., Hansen, M. (2003), 'Is the proportion of college workers in non-college jobs increasing', Journal of Labor Economics, 21, 449-471.

Green, P., McIntosh, S., Vignoles, A. (2002), 'The utilization of education and skills: evidence from Britain', The Manchester School, 70, 792-811.

Groot, W., Maassen van den Brink, H. (2000), 'Overeducation in the labour market: a meta-analysis', Economics of Education Review, 19, 149-158.

Hartog, J. (2000), 'Overeducation and earnings: where are we, where should we go?', Economics of Education Review, 19, 131-147.

Leckie, G., Charlton, C. (2011), Runmlwin: Stata module for fitting multilevel models in the MLwiN software package, Centre for Multilevel Modeling, University of Bristol.

McGuinness, S. (2003), 'University quality and labour market outcomes', Applied Economics, 35, 1943-1955.

McGuinness, S. (2006), 'Overeducation in the labour market', Journal of Economic Surveys, 20, 387-418.

OECD (1994), Employment Outlook, OECD, Paris.

OECD (2004), Employment Outlook, OECD, Paris.

OECD (2008), Main Science \& Technology Indicators, OECD, Paris.

OECD (2010), Indicators on Employment Protection - annual time series data 1985-2008, OECD, Paris.

Okun, A. (1981), Prices and Quantities: A Macroeconomic Analysis, Brookings Institution, Washington D.C.

Oosterbeek, H., Webbink, D. (1997), 'Is there a hidden technical potential?', De Economist, 145, $159-177$.

Robst, J. (1995), 'College quality and overeducation', Economics of Education Review, 14, 221-228. 
Robst, J. (2007), 'Education and job match: The relatedness of college major and work', Economics of Education Review, 26, 397-407.

Robst, J. (2008), 'Overeducation and college major: expanding the definition of mismatch between schooling and jobs', The Manchester School, 76, 349-368.

Rochat, D., Demeulemeester, J. (2001), 'Rational choice under unequal constraints: the example of Belgian higher education', Economics of Education Review, 20, 15-26.

Sicherman, N., Galor, O. (1990), ‘A theory of career mobility’, Journal of Political Economy, 98, 169-192.

Thurow, L. (1975), Generating Inequality: Mechanisms of distribution in the U.S. economy, Basic Books, New York.

Venn, D. (2009), 'Legislation, collective bargaining and enforcement: Updating the OECD employment protection indicators', OECD Working Papers, 89, 54p.

Verhaest, D., Omey, E. (2009), 'Objective over-education and worker well-being: a shadow price approach', Journal of Economic Psychology, 30, 469-481.

Verhaest, D., Van der Velden, R. (2013), 'Cross-country differences in graduate overeducation', European Sociological Review, 29, 642-653.

Wieling, M., Borghans, L. (2001), 'Discrepancies between supply and demand and adjustment processes in the labour market', Labour, 15, 33-56.

Wolbers, M. (2003), 'Job mismatches and their labour-market effects among school-leavers in Europe', European Sociological Review, 19, 249-266. 
Table 1: The incidence of mismatch five years after graduation

\begin{tabular}{|c|c|c|c|c|}
\hline & Full match & $\begin{array}{l}\text { Mere vertical } \\
\text { mismatch }\end{array}$ & $\begin{array}{l}\text { Mere horizontal } \\
\text { mismatch }\end{array}$ & Full mismatch \\
\hline Portugal & 0.855 & 0.079 & 0.040 & 0.026 \\
\hline Norway & 0.829 & 0.105 & 0.022 & 0.043 \\
\hline Finland & 0.829 & 0.073 & 0.060 & 0.037 \\
\hline France & 0.805 & 0.061 & 0.084 & 0.051 \\
\hline Switzerland & 0.804 & 0.071 & 0.071 & 0.054 \\
\hline Slovenia & 0.803 & 0.078 & 0.065 & 0.054 \\
\hline Germany & 0.793 & 0.086 & 0.066 & 0.055 \\
\hline Belgium & 0.777 & 0.082 & 0.069 & 0.073 \\
\hline Estonia & 0.776 & 0.049 & 0.156 & 0.019 \\
\hline Czech Republic & 0.768 & 0.064 & 0.114 & 0.054 \\
\hline Netherlands & 0.761 & 0.057 & 0.124 & 0.057 \\
\hline Austria & 0.752 & 0.070 & 0.118 & 0.060 \\
\hline Italy & 0.724 & 0.119 & 0.074 & 0.084 \\
\hline Poland & 0.707 & 0.058 & 0.158 & 0.077 \\
\hline Spain & 0.689 & 0.116 & 0.045 & 0.151 \\
\hline Hungary & 0.677 & 0.143 & 0.073 & 0.107 \\
\hline United Kingdom & 0.609 & 0.065 & 0.184 & 0.143 \\
\hline Japan & 0.399 & 0.050 & 0.349 & 0.203 \\
\hline Country average & 0.742 & 0.079 & 0.104 & 0.075 \\
\hline
\end{tabular}

Data source: REFLEX and HEGESCO, own calculations, based on weighted data. 
Table 2: Variance decomposition for alternative model specifications

\begin{tabular}{|c|c|c|c|c|c|}
\hline & Model 0 & Model 1 & Model 2 & Model 3 & Model 4 \\
\hline \multicolumn{6}{|l|}{ Variance decomposition of mere VMM } \\
\hline Unexplained var. individual level & 0.977 & 0.899 & 0.867 & 0.864 & 0.871 \\
\hline Unexplained var. field-of-study level & & & 0.047 & 0.034 & 0.034 \\
\hline Unexplained var. country level & 0.023 & 0.024 & 0.018 & 0.019 & 0.001 \\
\hline Explained variance & & 0.078 & 0.067 & 0.083 & 0.094 \\
\hline \multicolumn{6}{|l|}{ Variance decomposition of mere HMM } \\
\hline Unexplained var. individual level & 0.862 & 0.846 & 0.819 & 0.795 & 0.771 \\
\hline Unexplained var. field-of-study level & & & 0.064 & 0.007 & 0.008 \\
\hline Unexplained var. country level & 0.138 & 0.112 & 0.071 & 0.081 & 0.011 \\
\hline Explained variance & & 0.042 & 0.046 & 0.116 & 0.209 \\
\hline \multicolumn{6}{|l|}{ Variance decomposition of full MM } \\
\hline Unexplained var. individual level & 0.901 & 0.808 & 0.749 & 0.744 & 0.736 \\
\hline Unexplained var. field-of-study level & & & 0.126 & 0.016 & 0.012 \\
\hline Unexplained var. country level & 0.099 & 0.109 & 0.054 & 0.075 & 0.014 \\
\hline Explained variance & & 0.082 & 0.071 & 0.165 & 0.238 \\
\hline \multicolumn{6}{|l|}{ Model Specification } \\
\hline Variables Individual level & No & Yes & Yes & Yes & Yes \\
\hline Variables Field-of-study level & No & No & No & Yes & Yes \\
\hline Variables Country level & No & No & No & No & Yes \\
\hline Random effect Field-of-study level & No & No & Yes & Yes & Yes \\
\hline Random effect Country level & Yes & Yes & Yes & Yes & Yes \\
\hline
\end{tabular}


Table 3: The probability to have a mismatch five years after graduation - multinomial logit multilevel coefficient estimates - full model specification (Reference $=$ Full Match)

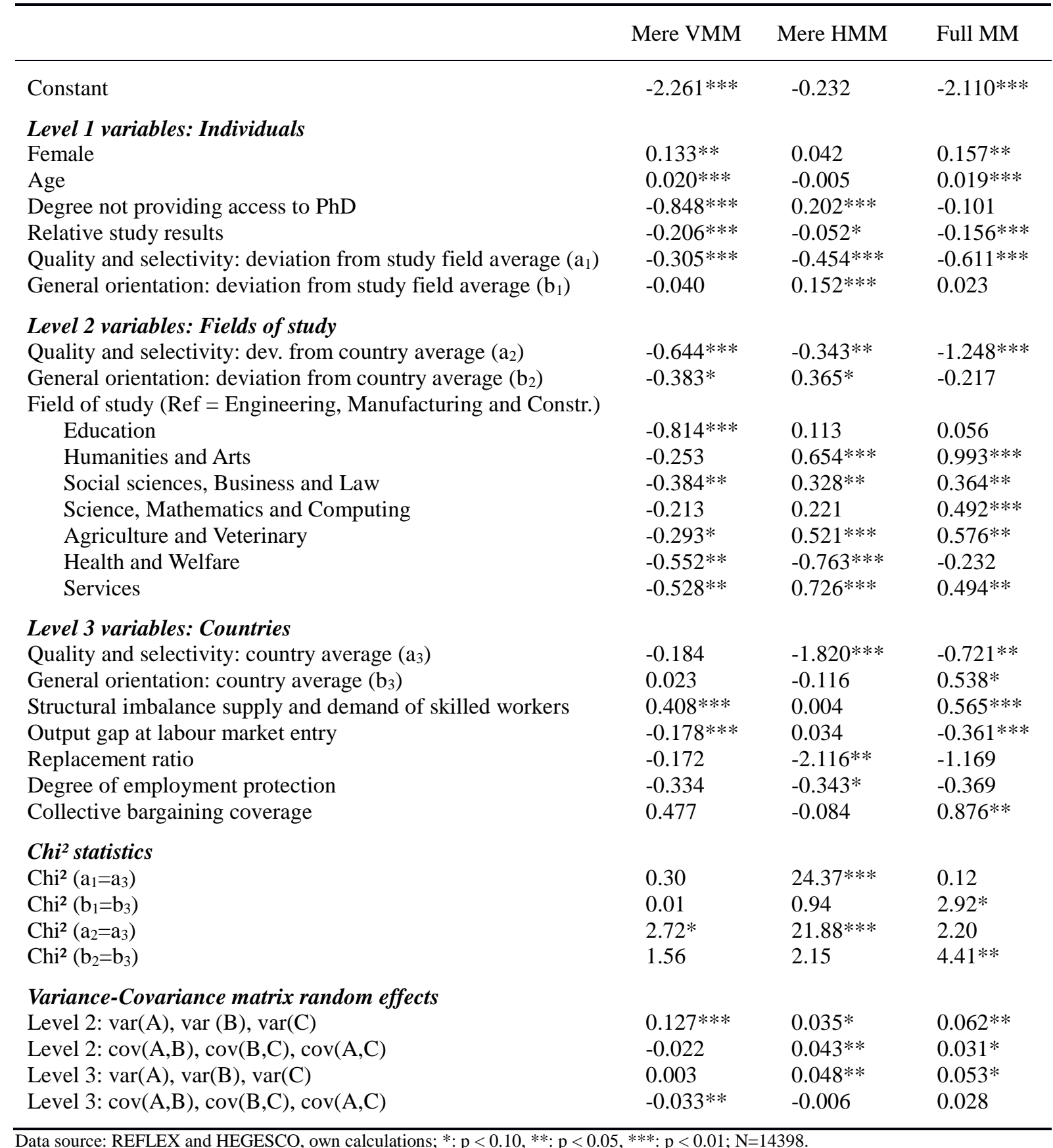

Data source: REFLEX and HEGESCO, own calculations; * $\mathrm{p}<0.10, * * \mathrm{p}<0.05$, ***: $\mathrm{p}<0.01 ; \mathrm{N}=14398$. 
Table 4: The probability to have a mismatch five years after graduation - multinomial logit multilevel coefficient estimates - reduced model specification $($ Ref = Full Match)

\begin{tabular}{lccc}
\hline & Mere VMM & Mere HMM & Full MM \\
\hline Level 3 variables: Countries & & & \\
Quality and selectivity: country average & - & $-1.894^{* *}$ & $-0.613^{* *}$ \\
General orientation: country average & - & - & $0.676^{* *}$ \\
Structural imbalance demand and supply of skilled workers & $0.404^{* * *}$ & - & $0.583^{* * *}$ \\
Output gap at labour market entry & $-0.181^{* * *}$ & - & $-0.412^{* * *}$ \\
Replacement ratio & - & $-1.596^{* *}$ & - \\
Degree of employment protection & $-0.330^{* *}$ & $-0.389^{* *}$ & $-0.489^{* *}$ \\
Collective bargaining coverage & $0.430^{* *}$ & - & $0.949 * *$
\end{tabular}

Included but not reported variables at level 1 and 2: see table 3; Data source: REFLEX and HEGESCO, own calculations; *: $\mathrm{p}<0.10$, , $^{*}: \mathrm{p}$ $<0.05, * * * \mathrm{p}<0.01 ; \mathrm{N}=14398$. 